\title{
Limites para a inovação e pesquisa na reforma psiquiátrica
}

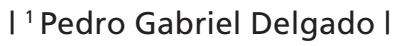

${ }^{1}$ Núcleo de Pesquisa em Políticas Públicas de Saúde Mental (NUPPSAM)/IPUB. Universidade Federal do Rio de Janeiro. Rio de JaneiroRJ. Brasil. Endereço eletrônico: pgabriel@ipub.ufrj.br

Nos últimos anos, desde uma série de artigos temáticos publicados em 2007, a revista inglesa Lancet abraçou a causa da superação da imensa lacuna de tratamento na área da saúde mental, problema existente nos países centrais com política universalista de saúde, mas muito mais grave entre os países pobres ou em desenvolvimento. Esse desafio continua sendo hoje uma das prioridades estratégicas para a saúde no mundo (LANCET, 2014). ${ }^{1}$ O Brasil é um dos poucos países de renda média ou baixa onde está em curso um processo consistente de ampliação do acesso ao tratamento, que vem sendo realizado através dos vetores da desinstitucionalização e da criação de serviços de base comunitária (OMS, 2006). O processo enfrenta hoje barreiras importantes, que precisam ser mais bem avaliadas, apresentando, ademais, notável fragilidade no campo da produção de conhecimento aplicado à condução prática dos dispositivos de atenção.

\section{Avanços alcançados na mudança do modelo e ampliação do acesso}

Em 2001 foi aprovada a Lei no 10.216, aclamada em seguida na grande celebração política da III Conferência Nacional de Saúde Mental, produzindo condições objetivas para anos sucessivos de avanço na política pública. A concentração hospitalar dos recursos financeiros (que chegou a 94\%) e humanos deu lugar à progressiva implantação da atenção psicossocial no território. Em 2006, deuse a virada definitiva da curva do financiamento: a maior parte dos recursos passou a ser direcionada para os Centros de Atenção Psicossocial, Residências Terapêuticas e demais dispositivos no território. A saúde mental pública 
deixava de ser hospitalocêntrica, mesmo que a matriz da institucionalização de tipo goffmanniano ainda permaneça como grande obstáculo a ser superado, recuperando agora sua força com os milhares de vagas para usuários de drogas, em comunidades terapêuticas fechadas e de longa permanência. A redução foi de mais de 35.000 leitos psiquiátricos tradicionais em 14 anos, substituídos pelo acolhimento mais humanizado nos serviços comunitários e nas internaçôes de curta duração. Foi necessário criar 2.200 serviços comunitários destinados à atenção diária de pacientes mais graves, além de 680 (número muito insuficiente) residências terapêuticas para os antigos moradores dos asilos. $\mathrm{Na}$ atenção primária, tecnologias que sequer existiam no país há apenas dez anos atrás foram mobilizadas e inventadas, mirando sabiamente sólidos exemplos estrangeiros (como a Inglaterra), para estender mais amplamente ao território o atendimento em saúde mental. Uma invenção de 2005 reuniu as políticas de Economia Solidária às oficinas de geração de renda e trabalho, criando um movimento ainda frágil, mas promissor, para abrir caminhos para a inclusão social de pacientes e familiares. Os avanços são reais, os retrocessos e barreiras, significativos, mas chama a atenção a notável carência de análises sistemáticas e objetivas, capazes de construir uma compreensão abrangente sobre o processo complexo de inovação e mudança paradigmática do modelo de atenção que vem ocorrendo na saúde mental do SUS.

Se, na reforma psiquiátrica do Brasil, a desinstitucionalização é italiana e a atenção comunitária, inglesa, as inovaçôes tecnológicas produzidas aqui, nossas jabuticabas, não são capricho de militantes, mas ousadias indispensáveis para fazer frente ao desafio da garantia de acesso com qualidade. O grau de protocolização desejável para a saúde mental no território é certamente menor que aquele de outras clínicas, embora seja necessário desvelar a fragilidade notável e reconhecida da rede de saúde mental: a baixa densidade dos consensos técnicos praticados. As inovações - como os consultórios de rua, na política de drogas, ou o matriciamento da saúde mental através dos Núcleos de Apoio à Saúde da Família, ou mesmo a diversificação dos tipos de CAPS - somente serão efetivas e sustentáveis se houver uma cultura enraizada de registro regular das ações desenvolvidas, de avaliação, supervisão, pesquisa. Isto é tudo que não existe na saúde mental do SUS, por responsabilidade de todos nós - academia, gestores, trabalhadores. 


\section{Desafios atuais e fragilidades}

Um elenco sumário das fragilidades e desafios da reforma psiquiátrica deve obrigatoriamente citar:

a) graves problemas na gestão dos serviços, que vão desde deficiências na estrutura (serviços comunitários instalados precariamente; vínculos profissionais fragilizados pela tendência avassaladora da terceirização), nos processos (baixíssima consolidação de consensos técnicos para funcionamento das equipes nos vários dispositivos da rede de atenção; ausência de mecanismos de avaliação permanente) e nos resultados (disparidade entre a efetividade de serviços mesmo em contextos semelhantes; critérios pouco claros de cobertura territorial efetiva, impedindo avaliação de impacto);

b) fragilidade da articulação com a atenção básica, problema que não pode ser enfrentado apenas pela burocratização das ações nas redes de atenção, mas pela abordagem sistemática do diálogo entre os modelos teóricos diversos que sustentam atenção primária e atenção psicossocial;

c) baixa densidade de articulação das açôes intersetoriais, significando impacto muito pequeno das recomendaçôes da IV Conferência Nacional de Saúde Mental - Intersetorial, de 2010;

d) ausência de estratégia clara para enfrentar a vulnerabilidade social, não só no campo das drogas, onde a política pública submeteu-se à pauta do pânico social amplificado pelos meios de comunicação, mas nas situações envolvendo diversas manifestações da violência e do desamparo social, cuja interface com a saúde mental oferece caminho propício para a abordagem das políticas públicas intersetoriais.

Em articulação com os desafios apontados acima, emerge com destaque a importante barreira da produção do conhecimento em atenção psicossocial.

\section{Limites estruturais para a pesquisa e pós-graduação em atenção psicossocial}

É uma questão de perspectiva. Houve importante aumento, a partir de 2008, no número de artigos em periódicos científicos rastreados por descritores que nomeiam as inovações tecnológicas produzidas na saúde mental do 
SUS, produtos não patenteados da reforma psiquiátrica. Artigos sobre CAPS são relativamente numerosos (mas uma gota d'água no oceano de estudos farmacológicos ou epidemiológicos); trabalhos sobre residências terapêuticas são raríssimos; a estratégia de redução de danos surge esparsamente; o dispositivo do matriciamento é citado em duas dezenas de artigos; pesquisas sobre pacientes de longa permanência aparecem em número muito menor que as relevantes experiências de desinstitucionalização que dignificam a história da reforma; consultórios de rua praticamente não aparecem: embora recentes na política pública, pois vêm de 2009, já poderiam, por sua importância como inovação, ter sido tomados como objeto de pesquisa.

Devemos comemorar o aumento numérico dos artigos. Tomando-se uma perspectiva processual e comparativa, entretanto, é importante ressaltar, na produção científica do campo da atenção psicossocial: a) número extremamente pequeno de artigos em periódicos indexados (apesar da tendência de incremento); b) poucos artigos produzidos como resultado de pesquisa de média e longa duração - predominam relatos de pesquisa de menor fôlego e investimento, ou ensaios; c) iniquidade da distribuição regional (reproduzindo a iniquidade da riqueza e da ciência no Brasil, mais de 90\% dos artigos concentram-se no Sudeste e Sul); e d) baixíssima participação em periódicos do campo da biomedicina.

Destaca-se ainda que: a) a maior parte dos artigos originam-se de cerca de cinco centros de pesquisa, evidenciando uma concentração explicável pela fragilidade geral da pesquisa neste campo e pelas características igualmente concentradoras da política de pesquisa; b) pequena produção em mestrado e doutorado, se comparado com Biomedicina e Epidemiologia. Neste aspecto, a quase totalidade das dissertações e teses são do campo da Saúde Coletiva, Ciências Humanas e Enfermagem, sendo numericamente irrisória a produção caraterizável como "atenção psicossocial” nos programas de pós-graduação em medicina. Esta inflexão tem relevância no caso brasileiro, por conta da disputa de modelos (biomédico ou psicossocial) que impactam a formação dos profissionais de medicina.

\section{Caminhos para a pesquisa em atenção psicossocial}

Estamos diante de um bom problema. Intrincado, porém nascido do avanço da saúde mental pública, e das dificuldades do SUS em cumprir seu papel estratégico 
na política pública de pós-graduação e pesquisa. Ele pode ser desdobrado em três perguntas, entre outras possíveis.

Como superar as barreiras estruturais da política de pesquisa no Brasil? A estrutura do fomento à pesquisa no Brasil é sabidamente rígida, não favorecendo a ampliação horizontal da base de pesquisadores. É concentradora e excludente. Porém, poderá ser sensível a propostas estratégicas, abrindo caminhos para o fortalecimento das inovaçôes que a saúde mental pública requer. Os gestores da política têm que tomar a iniciativa, pois certamente a CAPES e o CNPq não se moverão.

Mas a questão não é só política. O desafio epistemológico talvez seja mais espinhoso. No campo biomédico, por exemplo, como integrar a "Medicina Narrativa" com a Medicina Baseada em Evidências? Sabemos os efeitos que a reificação da evidence-based medicine significou para a formação médica (GREENHALG, 2013). No campo da saúde mental pública, esta simplificação enganadora (evidência versus não evidência) tomou contornos de luta política. Novamente aqui, a iniciativa deve ser dos pesquisadores da atenção psicossocial, pois não será dos autores dos ensaios randomizados controlados (RCT), que estão muito bem e confortáveis, iluminando o conhecimento em saúde mental. Aliás, também essa oposição é enganosa. Na Inglaterra, são os RCTs que dão sustentabilidade a inovações tipicamente psicossociais, como as equipes de tratamento assertivo (assertive care teams) e de acompanhamento em casa (home treatment).

Finalmente, um desafio de método. Como construir percursos metodológicos que mais efetivamente possam dar conta dos temas da vulnerabilidade social e da análise de intervençôes psicossociais complexas (por exemplo, entre outros, na interface com as medidas socioeducativas, ou com o consumo prejudicial de drogas, ou nos contextos de violência urbana armada)?

\section{Referências}

GREENHALG, T. Como ler artigos cientificos. Fundamentos da medicina baseada em evidências. Porto Alegre: Artmed, 2013.

LANCET. Global mental health: policy, progress, and prospects (Editorial). Lancet [www. thelancet.com], v. 384, Dec 6, 2014.

ORGANIZAÇÃO MUNDIAL DA SAÚDE. Organização Pan-Americana da Saúde. 15 anos depois de Caracas. Carta de Brasília, 2006. Disponível em: <http://bvsms.saude.gov.br/ bvs/publicacoes/Relatorio15_anos_Caracas.pdf>. Acesso em: jan 2015. 
${ }^{1}$ O desafio de vencer o treatment gap está no centro do Plano Global de Saúde Mental da OMS para 2013-2020 (ver http://apps.who.int/iris/bitstream/10665/89966/1/9789241506021_eng.pdf?ua=1). 